Article

\title{
Preparation and Characterization of Zinc Hydroxystannate Coated by Aluminum Phosphate and Its Application in Poly(acrylonitrile-co-vinylidene chloride)
}

\author{
Ji Eun Song ${ }^{1}$, Ji Su Kim ${ }^{1,2}$, Daeyoung $\operatorname{Lim}^{1}$ and Wonyoung Jeong ${ }^{1, *(D)}$ \\ 1 Human Convergence Technology R\&D Department, KITECH, Ansan 15588, Korea; \\ mplala@kitech.re.kr (J.E.S.); nrhope2@kitech.re.kr (J.S.K.); zoro1967@kitech.re.kr (D.L.) \\ 2 Department of Organic and Nano Engineering, Hanyang University, Seoul 04763, Korea \\ * Correspondence: wyjeong@kitech.re.kr
}

Received: 7 May 2020; Accepted: 12 June 2020; Published: 17 June 2020

check for updates

\begin{abstract}
In this study, zinc hydroxystannate ([ZnSn $\left.\left.(\mathrm{OH})_{6}\right], \mathrm{ZHS}\right)$ was coated with aluminum phosphate $\left(\mathrm{AlPO}_{4}, \mathrm{ALP}\right)$ to prepare the ZHS-ALP composite. During the coating process, the reaction conditions, such as the ALP to ZHS molar ratio, were controlled, and the morphology of the products was characterized by scanning electron microscopy (SEM). The prepared composites were introduced into poly(acrylonitrile-co-vinylidene chloride) (PANVDC), and the change in compatibility between ZHS and the polymer matrix was characterized. The results showed that ALP-ZHS (1:1), which was prepared by ALP-ZHS composite molar ratio of 1:1, could improve the dispersion and compatibility of ZHS in the polymer matrix and decrease the hydrophilicity and viscosity. Moreover, the ALP-ZHS composite had a better flame-retardant effect on PANVDC than ZHS alone. PANVDC could pass the $\mathrm{V}-0$ rating in UL94, particularly the highest limiting oxygen index (LOI) value of $33.2 \%$ obtained when the ALP-ZHS (1:1) composite was added to PANVDC.
\end{abstract}

Keywords: flame retardant; zinc hydroxystannate; modacrylic fiber; aluminum phosphate; zinc hydroxystannate coating

\section{Introduction}

Halogenated flame retardants are used widely in reducing the fire hazards of polymeric materials. On the other hand, the halogen-containing flame retardants usually cause serious environmental contamination because they can produce poisonous substances during the combustion of halogen-containing composites [1]. Therefore, halogen-free and low smoke fire retardant composites have been applied in polymer matrices because of their desired environmental acceptance. Among them, inorganic compounds are considered the most promising ones because they produce low smoke and low toxicity during combustion [2]. Zinc hydroxystannate $\left(\left[\mathrm{ZnSn}(\mathrm{OH})_{6}\right], \mathrm{ZHS}\right)$, which is an inorganic tin-containing compound, has critical advantages over many other flame retardants, such as low addition and high efficiency. Hence, it has been used as an effective halogen-free flame retardant in a wide range of polymeric materials [3]. Nevertheless, there are some limits in the manipulation of ZHS, which tend to aggregate, resulting in their non-uniform dispersion and poor compatibility in a polymer matrix [4].

To deal with the above problems, coating the ZHS surface is effective in improving the particular properties of ZHS. Depending on the type of coating material, the water resistance and compatibility of ZHS in the polymer matrix can be enhanced [5]. 
In previous related research, ZHS coatings were conducted using hydrated inorganic fillers, such as aluminum hydroxide (ATH) and magnesium hydroxide (MH) [6]. On the other hand, there have been few studies on ZHS coatings with organic group composites. Organic compounds are effective in improving the dispersion and thermal stability of the inorganic flame retardant in the polymer matrix.

Aluminum phosphate $\left(\mathrm{AlPO}_{4}, \mathrm{ALP}\right)$, which is included in the organic group composite, is effective in improving the dispersion and thermal stability of the inorganic flame retardant in the polymer matrix [1]. Therefore, in this study, ALP was selected as the coating material for ZHS to enhance the compatibility and flame retardancy of ZHS [7].

The primary purpose of this study was to improve the dispersion and compatibility between ZHS and the polymer matrix but maintain the flame retardancy of ZHS. For this, ZHS was coated by synthesizing with ALP (hereinafter, ALP-ZHS composite) and introduced into poly(acrylonitrile-co-vinylidene chloride) (PANVDC). The PANVDC, which is composed by co-polymerized acrylonitrile and vinylidene chloride, is an inherently flame resistant. Although it burns when directly exposed to flame, it does not melt and is self-extinguishing when the flame is removed. The flame retardancy of PANVDC can be improved by flame-retardant additives $[8,9]$. For this, the ALP-ZHS composite was first prepared, and the coating condition, such as the molar ratio of ALP against ZHS, was controlled by measuring the surface properties, viscosity, and flame retardancy of ALP-ZHS composite-doped PANVDC.

After introducing the ZHS and ALP-ZHS composites in the PANVDC, the changes in chemical properties were also characterized by Fourier transform infrared (FTIR) spectroscopy, X-ray photoelectron spectroscopy (XPS), X-ray diffraction (XRD), and thermogravimetric analysis (TGA). The flame-retardant properties of the PANVDC polymer were evaluated by vertical burning (UL94), limiting oxygen index (LOI), and micro combustion calorimeter (MCC).

Therefore, this assessed the coating method of ZHS by ALP and evaluated the effects of the compatibility, thermal stability, combustion performance, and chemical properties in PANVDC.

\section{Experimental}

\subsection{Materials}

Zinc hydroxystannate (ZHS, $\mathrm{ZnSn}(\mathrm{OH})_{6}$ ) was purchased from Ditto Technology Co., Ltd. (Gunpo, Korea). The following chemicals were obtained from Sigma Aldrich (St. Louis, Mo, USA): sodium dodecyl sulfate (SDS), cetyltrimethylammonium bromide (CTAB), and aluminum hydroxide $\left(\mathrm{Al}(\mathrm{OH})_{3}\right)$. PANVDC copolymer was a commercial flame retardant modacrylic with an AN to VDC. The weight average molecular weight of PANVDC was 170,000 Mw. Phosphoric acid $\left(\mathrm{H}_{3} \mathrm{PO}_{4}\right)$ procured from Alfa Aesar Co., Inc. (Lancashire, UK) and dimethyl sulfoxide (DMSO) acquired from Samchun Chemical Co., Ltd. (Seoul, Korea).

\subsection{Methods}

\subsubsection{Preparation of ZHS Composites Coated by ALP (ALP-ZHS Composite)}

In this paper, $\mathrm{H}_{3} \mathrm{PO}_{4}(98 \mathrm{~g} / \mathrm{mol})$ and $\mathrm{Al}(\mathrm{OH})_{3}(78 \mathrm{~g} / \mathrm{mol})$ were used as raw materials to prepare the aluminum phosphate $\left(\mathrm{AlPO}_{4}, \mathrm{ALP}\right)$. This study analyzed the reaction product and its polymerization extent under different coating conditions, such as the ALP molar ratio against ZHS.

The ZHS mixture was prepared by adding ZHS (10 g), SDS (0.02 g), and CTAB $(0.2 \mathrm{~g})$ to $200 \mathrm{~mL}$ of distilled water and dispersed ultra-sonication. After dispersion, aluminum hydroxide $\left(\mathrm{Al}(\mathrm{OH})_{3}\right)$ was added to the $\mathrm{ZHS}$ mixture at $\mathrm{Al}(\mathrm{OH})_{3}$ : $\mathrm{ZHS}$ molar ratio of 1:5, 1:1, 2:1 and phosphoric acid $\left(\mathrm{H}_{3} \mathrm{PO}_{4}\right)$ was also added at a $\mathrm{H}_{3} \mathrm{PO}_{4}$ : ZHS molar ratio of 1:5, 1:1, 2:1. Those samples are called ALP-ZHS(1:5), ALP-ZHS(1:1) and ALP-ZHS(2:1) composites. Each mixture was stirred at $50{ }^{\circ} \mathrm{C}$ for 
$1.5 \mathrm{~h}$ The ZHS composites coated by synthesizing ALP was centrifuged, washed several times with methanol, and dried overnight at $70^{\circ} \mathrm{C}$.

\subsubsection{Preparation of PANVDC Polymer-added ALP-ZHS Composite}

The flame-retardant PANVDC samples were prepared as follows. PANVDC ( $8.7 \mathrm{~g})$ was dissolved into DMSO solution $(21.3 \mathrm{~mL})$ in which ALP-ZHS composites were previously dispersed by ultra-sonication. ALP-ZHS composites were added by the amount $15 \%$ of the weight of PANVDC powder added. Depending on the ALP and ZHS molar ratio, the samples are called PANVDC/ALP-ZHS (1:5), PANVDC/ALP-ZHS (1:1), and PANVDC/ALP-ZHS (2:1), respectively. The dope was cast onto a glass substrate, pilled, and dried at $100{ }^{\circ} \mathrm{C}$ for $1 \mathrm{~h}$ to form a casting film.

\subsubsection{Characterization}

The morphological structures of the ALP-ZHS composites were examined by scanning electron microscopy (SEM, JSM-6700F, JEOL Ltd., Tokyo, Japan). The composites were immersed in liquid nitrogen and fractured. The water contact angle (WCA) of the films composed by PANVDC, PANVDC-doped ZHS (hereinafter, PANVDC-ZHS), and PANVDC/ALP-ZHS were measured using a WCA measurement system (SEO, Phoenix-MT (T), Suwon, Korea) and its software (Surface Ware 9, Surface Electro Optics, Suwon, Korea) [10].

The viscosity of the PANVDC polymer solutions, including the ZHS and ALP-ZHS composites, was measured using a rotational rheometer with a small sample adapter on the Brookfield DV2T Viscometer (AMETEK. Inc., Mass., USA), respectively. The measurements were conducted at $50{ }^{\circ} \mathrm{C}$ under $10 \mathrm{rpm}$. The ratio of viscosity change (\%) was calculated according to Equation (1).

$$
\text { Ratio of viscosity change }(\%)=\frac{V_{1}-V_{0}}{V_{1}} \times 100
$$

where $V_{0}$ is the viscosity of the polymer, and $V_{1}$ is the viscosity of the polymer-added ZHS and ALP-ZHS composites, respectively.

The chemical structures of the samples were analyzed by Fourier transform infrared (FTIR, FT/IR-670Plus, Jasco International Co. Ltd., Tokyo, Japan) spectroscopy was performed between $4000 \mathrm{~cm}^{-1}$ and $450 \mathrm{~cm}^{-1}$ at a resolution of $4 \mathrm{~cm}^{-1}$. The samples were ground and mixed at $2 \%$ in potassium bromide $(\mathrm{KBr})$. The baselines for each sample spectrum were normalized using spectrum software. The crystalline structures of the samples were characterized by powder XRD, D/MAX 2550V, D8 ADVANCE, BRUKER INC., Karlsruhe, Germany) using CuK radiation ( $\lambda=1.5418 \AA$; scanning speed: $0.5 / \mathrm{s}$.)

The vertical burning tests were conducted according to the UL94 (Underwriter's Laboratory, thin material vertical burning test) under controlled laboratory conditions. The UL94 test is performed with a $20 \mathrm{~mm}$ vertical flame by twice contacting a molded sample with dimensions of $127 \times 12.7 \times$ thickness in $\mathrm{mm}$ for $10 \mathrm{~s}$. To pass UL94 V2, the flame should extinguish within $30 \mathrm{~s}$ after each ignition. Burning drips are allowed. For UL94 V0 the flame should extinguish within $10 \mathrm{~s}$ after each ignition, with less than $50 \mathrm{~s}$ as total burn for 5 samples and no burning drips [11,12].

The LOI was tested according to ASTM D2863. The test specimens had dimensions of $100 \mathrm{~mm} \times$ $6.5 \mathrm{~mm} \times 3 \mathrm{~mm}[13,14]$. Thermogravimetric analysis (TGA, TA Q500, TA Instruments, New Castle, DE, USA) was performed from room temperature to $800^{\circ} \mathrm{C}$ at a heating rate of $20^{\circ} \mathrm{C} / \mathrm{min}$ in air [15].

A MCC test was conducted using a pyrolysis combustion flow calorimeter (Fire Testing Technology Ltd., East grinstead, UK), according to ASTM D 7309-19a [16]. Samples (5 mg) were exposed at a heating rate of $1 \mathrm{C} / \mathrm{s}$ and an $\mathrm{O}_{2}$ flow rate of $20 \mathrm{cc} / \mathrm{min}$. 


\section{Results and Discussion}

\subsection{Preparation of ALP-ZHS Composite}

Figure 1 shows the surface morphology of pure ZHS and ALP-ZHS composites prepared by different molar ratios of ALP against ZHS (1:5, 1:1, and 2:1), respectively. The surface of pure ZHS Figure 1a had a regular square shape with sharp edges. After ZHS was coated with ALP, the ZHS particles became globular in shape with the coated-like surface, which was an accumulation of many small particles of ALP [5]. The ALP-ZHS (1:1) composite Figure 1c was more spherical with a well-dispersed morphology, a uniform coating, and a particle diameter of $150 \mathrm{~nm}$ to $160 \mathrm{~nm}$. On the other hand, the ALP-ZHS (1:5) composite Figure 1b and ALP-ZHS (2:1) Figure 1d composites had irregularly coated particles, resulting in unstable and aggregated particles. In particular, the particle diameter of the ALP-ZHS (2:1) composite increased from around $80 \mathrm{~nm}$ (pure ZHS) to $225 \mathrm{~nm}$. This might be explained in terms of an imbalance between the ZHS particle size and the saturated mass of the coating material [2]. According to the results, the dispersion of ZHS particles in a polymer matrix could be increased by coating of ALP which has molar ratio of 1:1 against ZHS.
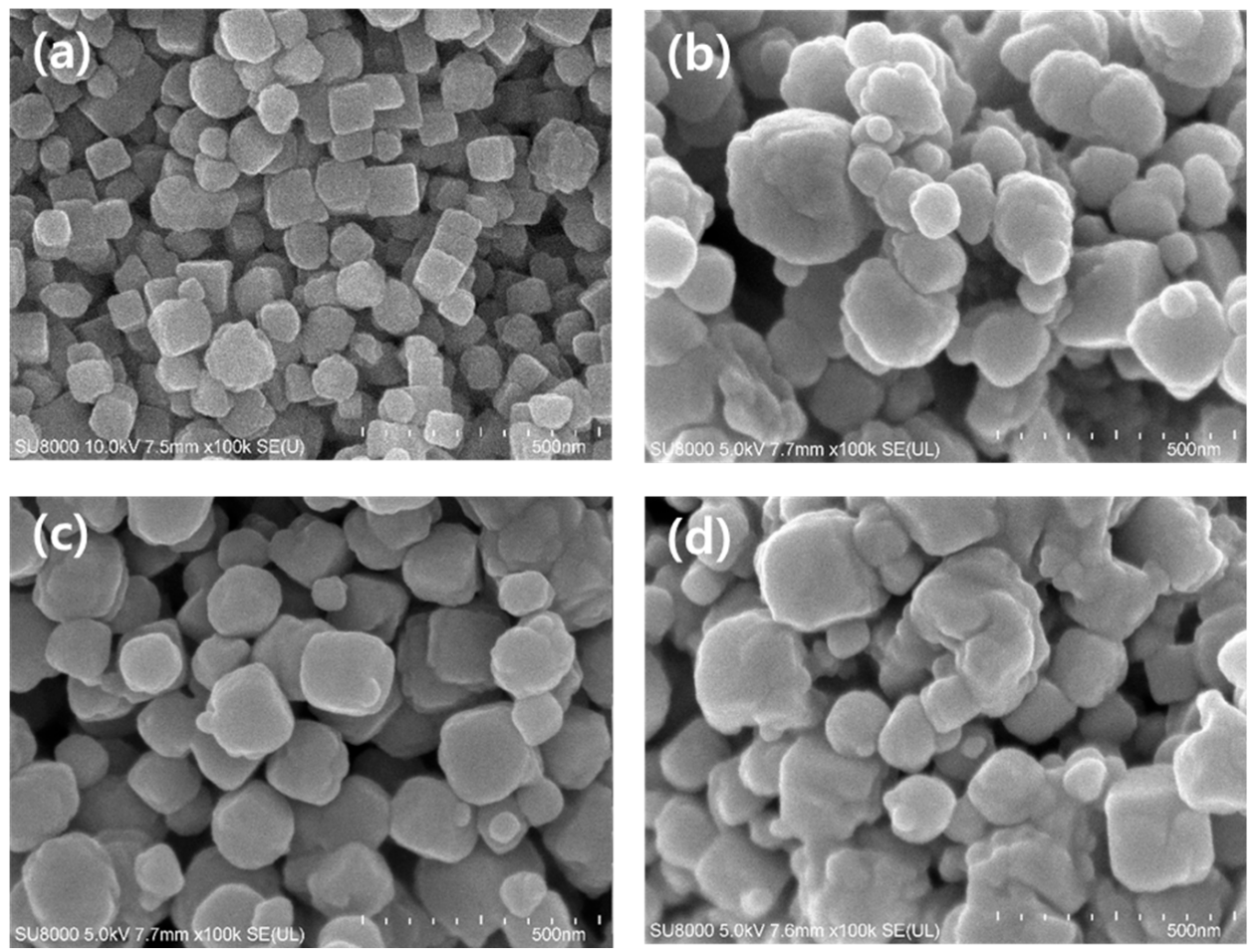

Figure 1. SEM images of (a) pure ZHS, (b) ALP-ZHS (1:5), (c) ALP-ZHS (1:1), and (d) ALP-ZHS (2:1) composites prepared at $50^{\circ} \mathrm{C}$ for $1.5 \mathrm{~h}$ (magnification: $\times 100,000$ ).

The coating technology facilitates converting the hydrophilicity of ZHS to hydrophobicity, which increases the compatibility of polymer matrix [2].

The WCA of the surface was measured to confirm the change in ZHS hydrophilic behavior after coating with ALP. As shown in Table 1, the WCA of the PANVDC decreased from $72 \pm 0.3$ to $36 \pm 1.5$ by adding ZHS. On the other hand, regarding the ALP coating on ZHS, the hydrophobicity of ZHS increased remarkably. In particular, the highest WCA was observed on the PANVDC/ALP-ZHS (1:1) composite. These results show that the ALP coating can be an effective method to reduce the water solubility of ZHS, which increases the compatibility of the composite materials and decreases the hygroscopicity of ZHS. 
Table 1. WCA of PANVDC, ZHS-PANVDC, and PANVDC films with ALP-ZHS composites prepared by different ALP molar ratios (1:5, 1:1, and 2:1) at $50{ }^{\circ} \mathrm{C}$ for $1.5 \mathrm{~h}$.

\begin{tabular}{cccccc}
\hline \multirow{2}{*}{ Characteristics } & \multirow{2}{*}{ PANVDC } & \multirow{2}{*}{ PANVDC-ZHS } & \multicolumn{3}{c}{ ALP Molar Ratio } \\
\cline { 4 - 6 } & & & $\mathbf{1 : 5}$ & $\mathbf{1 : 1}$ & $\mathbf{2 : 1}$ \\
\hline WCA $\left({ }^{\circ}\right)$ & $72 \pm 0.3$ & $36 \pm 1.5$ & $75 \pm 0.8$ & $82 \pm 0.5$ & $69 \pm 1.3$ \\
\hline
\end{tabular}

The effects of the ALP coating on the dispersion behavior of ZHS in the polymer composite were evaluated by measuring the change in polymer viscosity $(\mathrm{cP})$, which was converted to the ratio of viscosity change (\%). As shown in Figure 2, when ZHS alone was added to the PANVDC, the viscosity $(\mathrm{cP})$ of the PANVDC increased from 20,930 $\mathrm{cP}$ to $35,085 \mathrm{cP}$, along with a ratio of viscosity change (\%) of $68 \%$. The change in viscosity was attributed to the addition of flame-retardant contents in the polymer composites that would lead to unacceptable values of saturation $[17,18]$. On the other hand, after the ALP-ZHS composite was added to PANVDC, the ratio of viscosity change (\%) decreased significantly. In particular, the lowest viscosity change was obtained when ALP-ZHS (1:1) composite was added to the PANVDC. This was attributed to the improved hydrophobicity Table 1, indicating the enhanced compatibility.

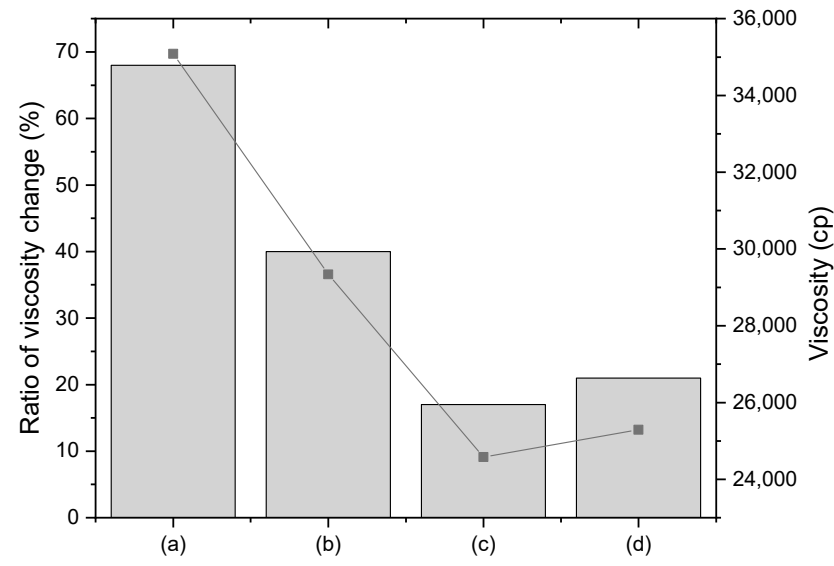

Figure 2. Viscosity (cP) at $100 \mathrm{rpm}$ and the ratio of viscosity change (\%); (a) PANVDC-ZHS, and PANVDC added (b) ALP-ZHS (1:5), (c) ALP-ZHS (1:1), and (d) ALP-ZHS (2:1) composites prepared at $50{ }^{\circ} \mathrm{C}$ for $1.5 \mathrm{~h}$.

A vertical flammability test (UL94) was performed to examine the effects of the ZHS and ALP-ZHS composite on the flame retardancy of the PANVDC. Table 2 lists the UL94 testing result and photographs of samples after the combustion process during $10 \mathrm{~s}$. Pure PANVDC burned immediately when exposed to the flame, and extinguished itself when the flame was removed. However, it burned up to $50 \%$ of the total sample length and the remained part was also blackened by smoke occurred while burning. In case of PANVDC added ZHS, 50\% of the total sample length was burned, and it presented a V-0 rating in the UL94 test. In addition, when adding ZHS-ALP composites, about 30\% of the sample was burned, especially when ALP-ZHS (1:1) was added, the PANVDC film extinguished a fire as soon as it was exposed to a flame then only $15 \%$ of the total sample length was burned. Thus, according to the addition of ZHS and ALP-ZHS composites in PANVDC, not only the burning time and but also the smoke behavior decreased.

The results suggest that ALP-ZHS effects on the flame retardancy of PANVDC, which is probably due to the shielding effect of ALP and the catalyzing charring effect of ZHS [19].

Therefore, the specific molar ratio of ALP against ZHS was concluded to be 1:1, considering the results, such as the decrease in viscosity and hydrophilicity, and retention of the flame retardancy of PANVDC. 
Table 2. Results of the vertical burning test (UL94) with the photographs of PANVDC, PANVDC-ZHS, and PANVDC/ALP-ZHS composites prepared at different ALP molar ratios (1:5, 1:1, and 2:1) at $50{ }^{\circ} \mathrm{C}$ for $1.5 \mathrm{~h}$.

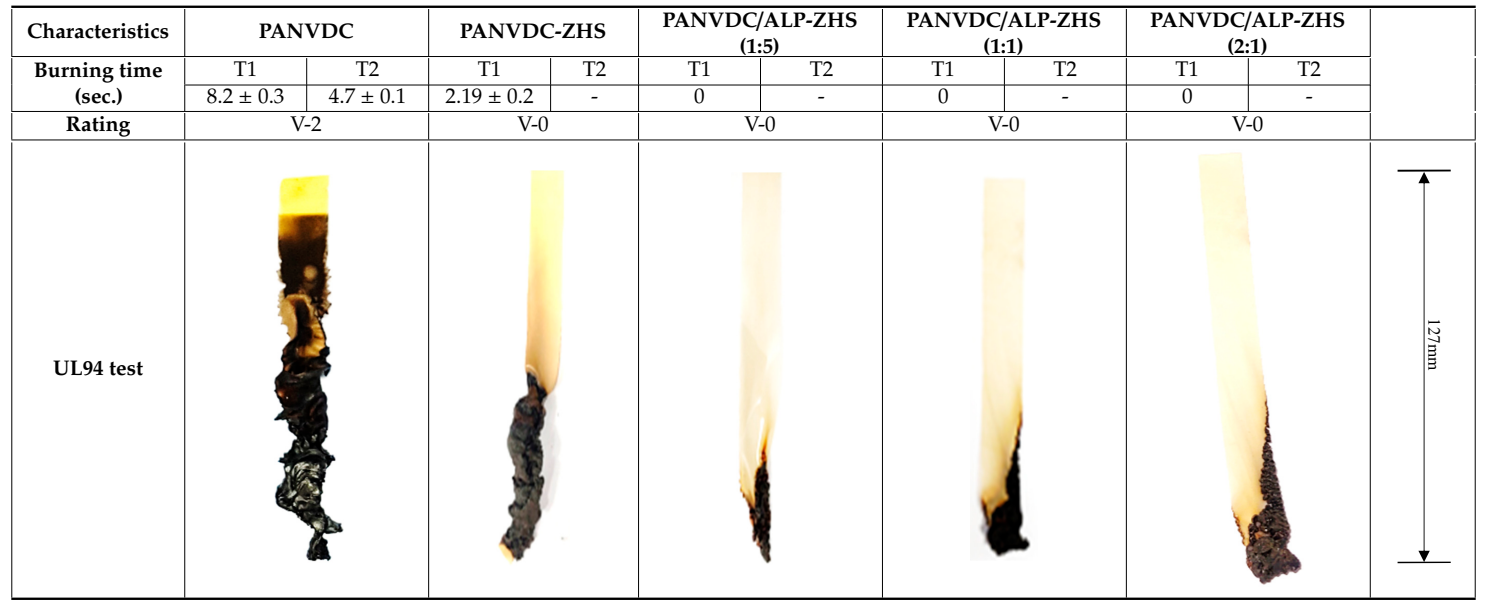

\subsection{Characterization of the PANVDC/ALP-ZHS}

Figure 3 shows the FTIR spectra of the pure ZHS and ALP-ZHS composites prepared under the controlled conditions. The characteristic peaks of ZHS were centered at 3126 and $1172 \mathrm{~cm}^{-1}$ and were assigned to the stretching vibrations of $\mathrm{O}-\mathrm{H}$ and $\mathrm{Sn}-\mathrm{O}$ bonds, respectively. In addition, the peak at $768 \mathrm{~cm}^{-1}$ was attributed to the stretching vibrations of $\left[\mathrm{Sn}(\mathrm{OH})_{6}\right]^{2-}$ belonging to ZHS [1]. After ZHS was coated with ALP, the spectra of pure ZHS was changed. The spectra of the ALP-ZHS (1:1) composite showed new absorption peaks. The band at $3619 \mathrm{~cm}^{-1}$ has been assigned to the surface $\mathrm{P}-\mathrm{OH}$ groups, demonstrating the existence of ALP [16,20,21]. In addition, the two peaks at $1018 \mathrm{~cm}^{-1}$ and $734 \mathrm{~cm}^{-1}$ were assigned to $\mathrm{P}=\mathrm{O}$ absorption bond in the phosphate and $\mathrm{Sn}-\mathrm{O}$ group vibrations, respectively. Consequently, FTIR confirmed that ZHS was coated successfully with ALP, and the ALP-ZHS composite had been prepared successfully [1].

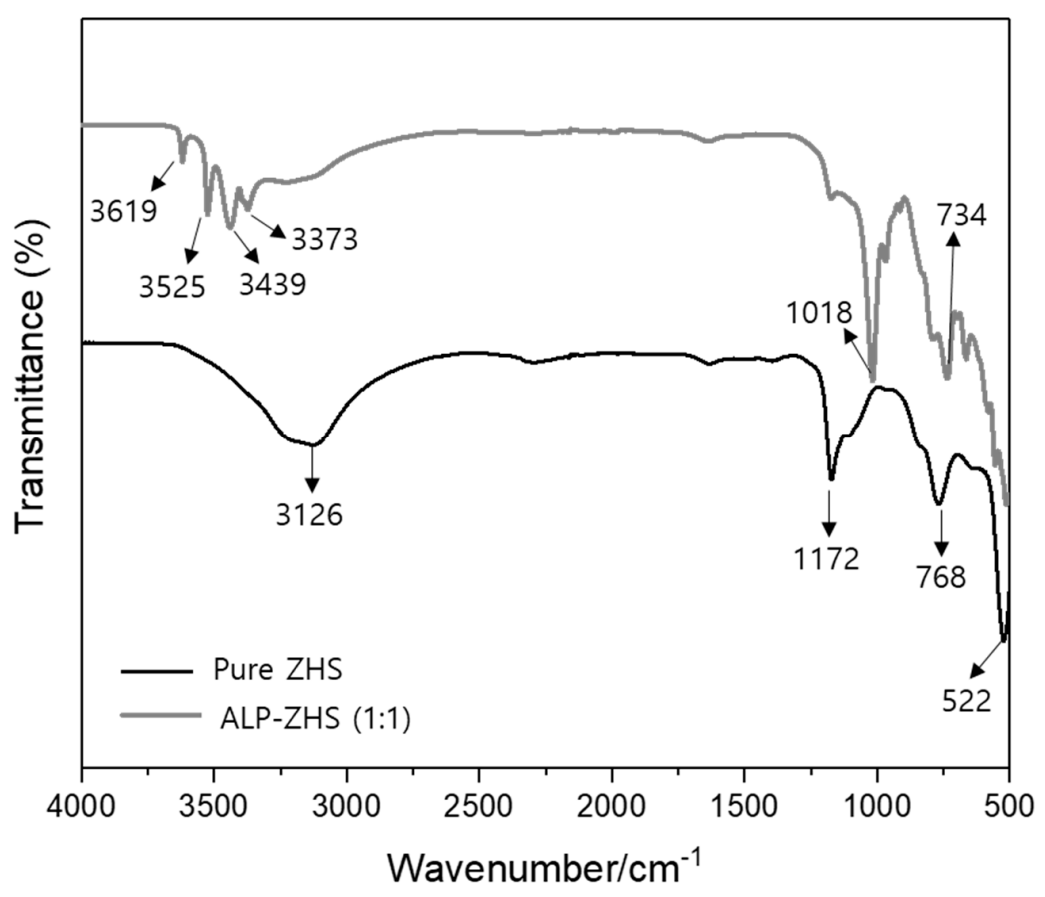

Figure 3. FT-IR spectra of pure ZHS, and ALP-ZHS (1:1) composite prepared at $50{ }^{\circ} \mathrm{C}$ for $1.5 \mathrm{~h}$. 
XRD was conducted to determine the composition and crystalline phase of the as-prepared samples. Figure 4 shows the XRD patterns of pure ZHS and ALP-ZHS (1:1) composite. As shown in Figure $4 \mathrm{a}$, the XRD peaks of pure ZHS were sharp, and the baselines were low. Four relatively strong peaks at $22.89^{\circ}, 32.56,40.16$, and $46.832 \theta$ were assigned to the (200), (220), (322), and (400) reflections of the $\mathrm{ZnSn}(\mathrm{OH})_{6}$, respectively. The sharp peaks suggest that the obtained $\mathrm{ZnSn}(\mathrm{OH})_{6}$ particles have good crystallinity and no impurity phases with well-formed crystalline layered structures. For a curve of ALP-ZHS composite Figure 4b, the characteristic diffraction adsorptions of ALP were observed at approximately 18 , and $21.52 \theta$ [22]. In the meantime, no other phases were detected by $X R D$, suggesting that the surface coating does not cause changes in the crystal structure of ZHS nanoparticles. Overall, ZHS was coated successfully by ALP under the controlled reaction conditions without damage to its original crystallinity structure.



Figure 4. XRD patterns of (a) pure ZHS and (b) ALP-ZHS (1:1) composite prepared at $50{ }^{\circ} \mathrm{C}$ for $1.5 \mathrm{~h}$.

Figure 5 presents the TGA curve of the PANVDC, PANVDC-ZHS, and PANVDC/ALP-ZHS composites, and Table 3 lists the data. The initial decomposition temperature $\left(\mathrm{T}_{\mathrm{d}}\right)$ can be considered the temperature at which $5 \mathrm{wt}$. \% weight loss occurs, and the temperature of the maximum mass loss rate $\left(\mathrm{T}_{\max }\right)$ is defined as the temperature at which the samples present the maximal mass loss rate. As shown in Figure 5, PANVDC showed a $T_{d}$ at $210{ }^{\circ} \mathrm{C}$ and two main stages with $T_{\max 1}$ at $302{ }^{\circ} \mathrm{C}$ and $\mathrm{T}_{\max 2}$ at $450^{\circ} \mathrm{C}$. The higher $\mathrm{T}_{\mathrm{d}}\left(\sim 210^{\circ} \mathrm{C}\right)$ of PANVDC than PANVDC-ZHS and PANVDC/ALP-ZHS can be explained by the $\mathrm{HCl}$ generated through dehydrohalogenation [23]. Up to $790{ }^{\circ} \mathrm{C}$, the residual weight of PANVDC was only 43 wt. $\%$.



Figure 5. TGA curves of PANVDC, PANVDC-ZHS, and PANVDC/ALP-ZHS (1:1) films. 
Table 3. TGA data of PANVDC, PANVDC-ZHS, and PANVDC/ALP-ZHS (1:1) films.

\begin{tabular}{ccccc}
\hline Samples & $\mathbf{T}_{\mathbf{d}}\left({ }^{\circ} \mathbf{C}\right)$ & $\mathbf{T}_{\max }\left({ }^{\circ} \mathbf{C}\right)$ & $\mathbf{T}_{\max 2}\left({ }^{\circ} \mathbf{C}\right)$ & Residue (wt. \%) \\
\hline PANVDC & 210 & 302 & 450 & 43 \\
PANVDC-ZHS & 190 & 305 & 505 & 51 \\
PANVDC/ALP-ZHS (1:1) & 190 & 305 & 510 & 56 \\
\hline
\end{tabular}

Regarding the PANVDC-ZHS and PANVDC/ALP-ZHS composites, the thermal degradation process also consisted of two main stages. From $300{ }^{\circ} \mathrm{C}$ to $450{ }^{\circ} \mathrm{C}$, PANVDC-ZHS and PANVDC/ ALP-ZHS composites decomposed slowly compared to PANVDC. This suggests that the addition ZHS enhances the thermal stability of PANVDC in a high thermal degradation process. In particular, the ALP-ZHS composite has better effects on PANVDC by increasing the pyrolysis temperature because the ALP material coated on ZHS had been exposed to the external environment and had a larger surface area, so it decomposed first [24]. In addition, active groups $(-\mathrm{OH})$ were present on the surface of the ALP-ZHS composite, which resulted in the formation of a crosslinking network structure composed of flame-retardant particles and polymer chains [25].

Consequently, the maximum mass loss rate of PANVDC/ALP-ZHS composite was $54 \mathrm{wt}$. \% higher than that of PANVDC and PANVDC-ZHS. TGA indicated that the addition of an ALP-ZHS composite could not change the mechanism of thermal degradation of PANVDC, but they could improve the PANVDC thermal stability of the polymer.

MCC is a useful technique for studying the relationship between the polymer chemical structure and combustion behavior based on oxygen consumption theory. Table 4 lists the relevant parameters obtained from the MCC test, such as the peak heat release rate (pHRR), time of the peak heat release rate $\left(\mathrm{T}_{\mathrm{PHRR}}\right)$, total heat release rate $(\mathrm{THR})$, and heat release capacity $(\mathrm{HRC})$.

Table 4. Results of MCC and LOI tests of pure PANVDC, ZHS-PANVDC, and PANVDC/ALP-ZHS (1:1) films.

\begin{tabular}{cccccc}
\hline Samples & PHRR (w/g) & T $_{\text {PHRR }}\left({ }^{\circ} \mathbf{C}\right)$ & THR (KJ/g) & HRC (J/g.K) & LOI (\%) \\
\hline PANVDC & 167 & 711 & 13 & 172 & 24 \\
\hline ZHS-PANVDC & 142 & 684 & 14 & 149 & 33 \\
\hline PANVDC/ALP-ZHS (1:1) & 96 & 734 & 12 & 114 & 33.2 \\
\hline
\end{tabular}

The PANVDC film added ALP-ZHS (1:1) composites had the lowest peak of HRC, which is in good agreement with the UL94 test and pHRR value [26]. The incorporation of ZHS decreased the pHRR of PANVDC composites to $142 \mathrm{w} / \mathrm{g}$ from $167 \mathrm{w} / \mathrm{g}$ of pure PANVDC. The ALP-ZHS (1:1) composite showed a significant decrease in the pHRR value of PANVDC to $96 \mathrm{w} / \mathrm{g}$, suggesting that the pure PANVDC burned very fast after ignition. In addition, the THR value of PANVDC decreased $13 \mathrm{KJ} / \mathrm{g}$ to $12 \mathrm{KJ} / \mathrm{g}$, and HRC value decreased from $172 \mathrm{~J} / \mathrm{g} \cdot \mathrm{K}$ to $114 \mathrm{~J} / \mathrm{g} \cdot \mathrm{K}$. These results were attributed to the shielding effect of ALP-ZHS composites, achieving the aims of synergistic flame retardancy. In addition, the barrier action of the char layer produced by the ALP-ZHS composite is expected to have important effect in hindering heat transfer and gas diffusion [27-29]. It is believed that the PO-radical plays the major role [29]. As a result, the charring of coated ZHS by ALP played a vital role in improving the flame retardancy behavior of PANVDC [5,17]. As a result of the LOI test, the LOI value of PANVDC increased drastically from 24 to $33 \%$ by the addition of ZHS. When ALP-ZHS (1:1) composites were added, the LOI value of PANVDC exhibited an insignificant increase while this value was still higher than the pure PANVDC. This shows that ZHS retained its original high flame retardancy, even after coating.

Therefore, the MCC and LOI test results demonstrate that the addition of ALP-ZHS (1:1) composite has a larger effect in reducing the heat release rate and total heat release and flame retardancy of PANVDC than the addition of ZHS alone. 


\section{Conclusions}

This study aimed to improve the dispersion and compatibility of ZHS in a flame-retardant polymer matrix. For this, the surface of ZHS was coated by synthesizing ALP then applying the ALP-ZHS composite to the PANVDC polymer. The ALP to ZHS molar ratio was to be 1:1. The results showed that ALP-ZHS (1:1) can improve the dispersion and compatibility of ZHS in the polymer matrix and decrease the hydrophilicity and viscosity.

Moreover, a well-dispersed morphology was confirmed in the PANVDC matrix doped ALP-ZHS composite without aggregated ZHS particles. The ALP-ZHS composite had a better flame-retardant effect on PANVDC than ZHS alone. PANVDC can pass the V-0 rating in UL94, particularly the highest LOI value of $33.2 \%$ obtained when ALP-ZHS (1:1) composite was added in PANVDC.

This study examined the improvement of ZHS compatibility when added to a polymer matrix, which is a simple and effective technique for controlling ZHS as a powerful flame-retardant material that can be applied to various practical applications.

Author Contributions: Conceptualization, J.E.S., J.S.K., and W.J.; investigation, J.E.S., and J.S.K.; writing-original draft preparation, J.E.S.; writing-review and editing, J.E.S., and W.J.; supervision, W.J., and D.L. All authors have read and agreed to the published version of the manuscript.

Funding: This research was supported by the "Industrial Material Technology Development Project (10063549)" funded by the Ministry of trade, Industry, and Energy.

Conflicts of Interest: The authors declare no conflict of interest.

\section{References}

1. Gao, T.T.; Li, Z.W.; Yu, L.G.; Zhang, Z.J. Preparation of zince hydroxystannate nanocomposites coated by organnophosphorus and investigation of their effect on mechanical properties and flame retardancy of poly (vinyl chloride). RSC. Adv. 2015, 5, 99291-99298. [CrossRef]

2. Zhang, B.; Han, J. Morphology control of zinc hydroxystannate microcapsules by sol-gel method and their enhanced flame retardancy properties for polyvinyl chloride composites. J. Sol-Gel Sci. Technol. 2016, 81, 442-451. [CrossRef]

3. Han, L.; Liu, J.; Wang, Z.; Zhang, K.; Luo, H.; Xu, B.; Zou, X.; Zheng, X.; Ye, B.; Yu, X. Shape-controlled synthesis of $\mathrm{ZnSn}(\mathrm{OH}) 6$ crystallites and their HCHO-sensing properties. CrystEngComm 2012, 14, 3380-3386. [CrossRef]

4. Zhang, B.; Liu, H.; Han, J. Synthesis of zinc hydroxystannate microcapsule for improving flame retardancy and smoke suppression of poly(lactic acid). Mater. Lett. 2018, 213, 35-39. [CrossRef]

5. Ge, H.; Tang, G.; Hu, W.Z.; Wang, B.B.; Pan, Y.; Song, L.; Hu, Y. Aluminum hypophosphite microencapsulated to improve its safety and application to flame retardant polyamide 6. J. Hazard. Mater. 2015, 294, $186-194$. [CrossRef]

6. Xu, J.; Zhang, C.; Qu, H.; Tian, C. Zinc hydroxystannate and zinc stannate as flame-retardant agents for flexible poly(vinyl chloride). J. Appl. Polym. Sci. 2005, 98, 1469-1475. [CrossRef]

7. Zhang, B.; Jiang, Y.; Han, J. The core-double-shell microcapsules flame retardant: Synthesis and its application for polyvinyl chloride composites. J. Phys. Chem. Solid 2017, 111, 391-402. [CrossRef]

8. Tanaka, T.; Terakado, O.; Hirasawa, M. Flame retardancy in fabric consisting of cellulosic fiber and modacrylic fiber containing fine-grained $\mathrm{MoO}_{3}$ particles. Fire Mater. 2016, 40, 612-621. [CrossRef]

9. Kim, H.A.; Kim, S.J. Flame-Retardant and Wear Comfort Properties of Modacrylic/FR-Rayon/Anti-static PET Blend Yarns and Their Woven Fabrics for Clothing. Fiber Polym. 2018, 19, 1869-1879. [CrossRef]

10. Jain, A.K.; Tesema, A.F.; Haile, A. Development of shrink resistance cotton using fluorocarbon. Fash. Text. 2019, 6, 1. [CrossRef]

11. Kaspersma, J.; Doumen, C.; Munro, S.; Prins, A.M. Fire retardant mechanism of aliphativc bromine compounds in polystyrene and polypropylene. Polym. Degrad. Stab. 2002, 77, 325-331. [CrossRef]

12. Lee, S.H.; Yi, G.R.; Yim, D.Y.; Jeong, W.Y.; Youk, J.H. Study on the Flame Retardant and Mechanical Properties of Wet-spun Poly(acrylonitrile-co-vinylchloride) Fibers with Antimony Trioxide and Zinc Hydroxystannate. Fiber Polym. 2019, 20, 779-786. [CrossRef] 
13. Yang, L.; Shi, C.L. Effect of Zinc Hydroxystannate Coated M-HOS Whisker on Flame Retardant Properties of Flexible PVC. Procedia Eng. 2018, 211, 901-905. [CrossRef]

14. ASTM D2863-19, Standard Test Method for Measuring the Minimum Oxygen Concentration to Support Candle-Like Combustion of Plastics (Oxygen Index); ASTM International: West Conshohocken, PA, USA, 2019.

15. Khanna, S.; Sharm, S.; Chakraborty, J.N. Performance assessment of fragrance finished cotton with cyclodextrin assisted anchoring hosts. Fash. Text. 2015, 2, 19. [CrossRef]

16. ASTM D7309-19a, Standard Test Method for Determining Flammability Characteristics of Plastics and Other Solid Materials Using Microscale Combustion Calorimetry; ASTM International: West Conshohocken, PA, USA, 2019.

17. De Fenzo, A.; Formicola, C.; Antonucci, V.; Zarrelli, M.; Giordano, M. Effects of zinc-based flame retardants on the degradation behaviour of an aerospace epoxy matrix. J. Polym. Degrad. Stab. 2009, 94, 1354-1363. [CrossRef]

18. Yang, L.; Hu, Y.; You, F.; Chen, Z. A novel method to prepare zinc hydroxystannate-coated inorganic fillers and its effect on the fire properties of PVC cable materials. Polym. Eng. Sci. 2007, 47, 1163-1169. [CrossRef]

19. Gao, T.; Chen, L.; Li, Z.; Yu, L.; Wu, Z.; Zhang, Z. Preparation of zinc hydroxystannate-decorated graphene oxide nanohybrids and their synergistic reinforcement on reducing fire hazards of flexible poly (vinyl chloride). Nanoscale Res. Lett. Title 2016, 11, 192. [CrossRef] [PubMed]

20. Tanaka, H.; Chikazawa, M. Modification of amorphous aluminum phosphate with alkyl phosphates. Mater. Res. Bull. 2000, 35, 75-84. [CrossRef]

21. Qian, X.; Song, L.; Yuan, B.; Yu, B.; Shi, Y.; Hu, Y.; Yuen, R.K.K. Organic/inorganic flame retardants containing phosphorus, nitrogen and silicon: Preparation and their performance on the flame retardancy of epoxy resins as a novel intumescent flame retardant system. Mater. Chem. Phys. 2014, 143, 1243-1252. [CrossRef]

22. Liu, H.; Zhang, B.; Han, J. Flame retardancy and smoke suppression properties of flexible polyurethane foams containing an aluminum phosphate microcapsule. RSC. Adv. 2017, 56, 35320-335329. [CrossRef]

23. Hwang, J.H.; Choi, H.W.; Lee, S.H.; Kim, G.H.; Jeong, W.Y.; Lim, D.Y.; Youk, J.H. Polymerization and Wet-spinning of Flame Retardant Poly(acrylonitrile-co-vinylidene chloride) Copolymers: Effect of Vinylidene Chloride Content. Polym. Korea 2018, 42, 1077-1084. [CrossRef]

24. Lagno, F.; Demopoulos, G.P. Synthesis of Hydrated Aluminum Phosphate, AlPO4-1.5H2O (AlPO4-H3), by Controlled Reactive Crystallization in Sulfate Media. Ind. Eng. Chem. Res. 2005, 44, 8033-8038. [CrossRef]

25. Luo, F.; Wu, K.; Lu, M.; Nie, S.; Li, X.; Guan, X. Thermal degradation and flame retardancy of microencapsulated ammonium polyphosphate in rigid polyurethane foam. J. Therm. Anal. Calorim. 2015, 120, 1327-1335. [CrossRef]

26. Chang, S.; Xie, T.; Yang, G. Structures and properties of wet spun thermo-regulated polyacrylonitrilevinylidene chloride fibers. Polym. Degrad. Stab. 2006, 91, 351-359.

27. Qu, T.G.; Yang, N.; Hou, J.; Li, G.H.; Yao, Y.M.; Zhang, Q.X.; He, L.Q.; Wu, D.Z.; Qu, X.W. Flame retarding epoxy composites with poly(phosphazene-co-bisphenol A)-coated boron nitride to improve thermal conductivity and thermal stability. RSC. Adv. 2017, 7, 6140-6151. [CrossRef]

28. Lai, X.; Tang, S.; Li, H.; Zeng, X. Flame-retardant mechanism of a novel polymeric intumescent flame retardant containing caged bicyclic phosphate for polypropylene. Polym. Degrad. Stab. 2015, 113, 22-31. [CrossRef]

29. Shartel, B. Phosphorus-based flame retardancy mechanisms-old hat or starting point for future development? Materials 2010, 3, 4710-4745. [CrossRef]

(C) 2020 by the authors. Licensee MDPI, Basel, Switzerland. This article is an open access article distributed under the terms and conditions of the Creative Commons Attribution (CC BY) license (http://creativecommons.org/licenses/by/4.0/). 